\title{
EARLY DEVELOPMENT OF OPHIOTAENIA PERSPICUA
}

LA RUE

KARL E. HERDE

Reprinted from Transactions of the American Microscopical Society Vol. LVII, No. 3, July, 1938 


\section{EARLY DEVELOPMENT OF OPHIOTAENIA PERSPICUA LA RUE}

BY

KARL E. HERDE

BACHELOR OF SCIENCE OKLAHOMA AGRICULTURAL AND MECHANICAL COLLEGE 1935

SUBMITTED TO THE DEPARTMENT OF ZOOLOGI

OKLAHOMA AGRICULTURAL AND MECHANICAL COLLEGE

IN PARTIAL FULFILLMENT OF THE REQUIREMENTS

FOR THE DEGREE OF MASTER OF SCIENCE

1937

APPROVED:

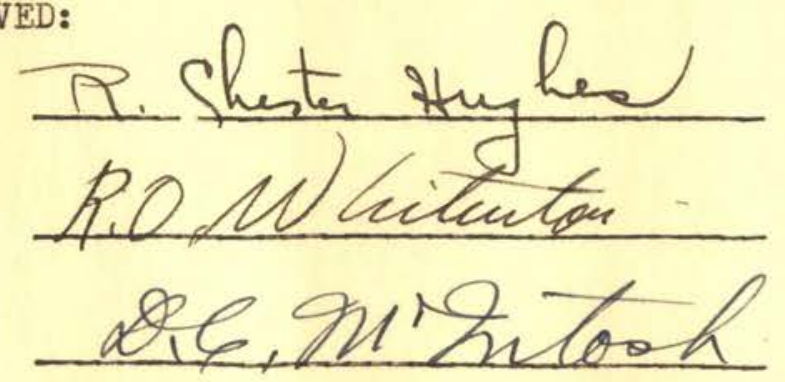

In Charge of Thesis

Head of the Department of $Z_{0 o l o g y}$

Dean of the Graduate School 
EARLY DEVELOPMENT OF OPHIOTAENIA PERSPICUA

LA RUE

\author{
OKLABONA \\ AGRICULTORAL \& MLCHANICAL COLLER \\ $L I B R A R Y$ \\ DCT 151938
}

\begin{abstract}
KARL E. HERDE
\end{abstract}

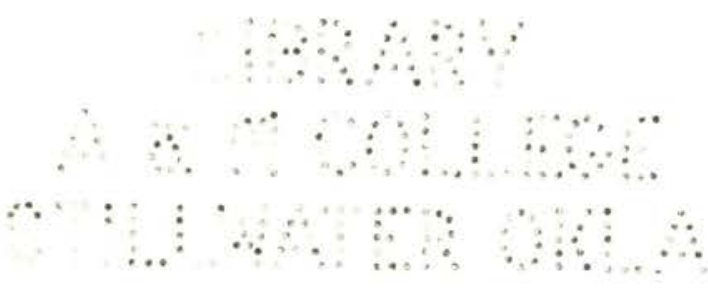

Reprinted from Transactions of the American Microscopical Society

Vol. LVII, No. 3, July, 1938 


\section{EARLY DEVELOPMENT OF OPHIOTAENIA PERSPICUA LA RUE*}

\section{KARL E. Herde}

This paper presents some observations on the structure of the oncosphere and the development of the procercoid of the proteocephalid tapeworm, Ophiotaenia perspicua La Rue. Species of the genus Ophiotaenia La Rue have also been variously assigned to the genera Proteocephalus Weinland, Ichthyotaenia Lönnberg, and Crepidobothrium Monticelli. Rather than undertake to settle questions of synonymy, I use the original name intending neither to question nor to certify its validity. The incidence of this tapeworm, at Stillwater, Oklahoma, in adult watersnakes, Natrix rhombifera (Hallowell), is about 60 per cent.

The cestode conforms closely to the structure of $O$. perspicua as described by La Rue (1911 and 1914) and Anderson (1935). These authors, however, apparently studied only preserved material and failed to note the very fine cuticular spination readily observable on living specimens. The spination is very dense over the scolex and anterior portion of the neck becoming gradually sparser posteriorly. The increasing relative scarcity may be due to a failure of the spines to increase in number as the proglottides enlarge. Spines were not observed on mature proglottides probably because of their scarcity and the greater thickness of the tissue.

A study by Joyeux and Baer (1929) on a worm tentatively identified as "Ichthyotaenia (Crepidobothrium) racemosa (Rudolphi, 1891) ... chez Tropidonotus natrix L." together with the prevalence of a plerocercoid, having four acetabula and an "end organ," in Helioperca macrochira (Rafinesque) in the same ponds from, which the infected snakes were collected, led me to suspect that the séries of hosts in the life cycle of this tapeworm was a cycłóps, a: ceńtrarchịd, and a water șnake - a theory which my experiments did ncit, en tirèly substantiate.

All observations on oncoşpheres ąnd-developing larvae in cyclopes were mảde on living máteriâl and alt measurements are from live specimens not subject to pressure. The measurements of the embryophores were taken from 20 specimens.

Living oncospheres were secured in large numbers by placing fresh gravid proglottides in tap water. Practically all fully-developed embryos and some less mature ones were soon discharged.

* Contribution from the Zoological Laboratory, Oklahoma Agricultural and Mechanical College, prepared under the direction of R. Chester Hughes.

I am greatly indebted to Mr. Eugene W. Hubbard for aid in collecting snakes and in other field work.

The snakes referred to in this paper were identified by the late Dr. F. N. Blanchard and the fish by Dr. Carl L. Hubbs, both of the University of Michigan. The copepods were identified by Dr. C. B. Wilson of the Massachusetts State Normal School, Westfield, Massachusetts. 


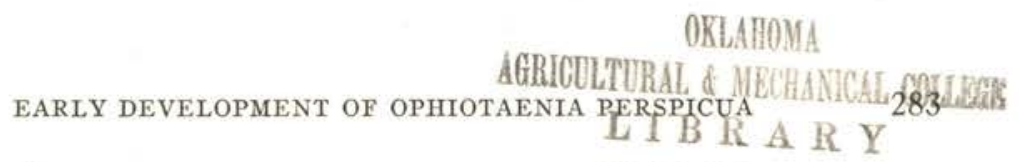

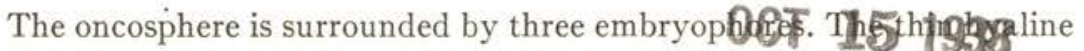
spheroidal outer membrane, diameter 58 to 149 (average 91) microns, has two opposed funnel-shaped depressions that extend inward to the middle membrane. Whether the outer membrane is non-perforate and merely in contact with the middle membrane at the bottoms of these polar funnels or whether the two funnels are continuous with each other forming a sheath about the middle membrane was not determined. The funnels are practically invisible when viewed in line with their common axis (figs. 17, 18). The funnels vary in shape from some that are broad and shallow (fig. 13), causing the outer embryophore to be flattened in their axis, to some that are deep, narrow, and elongate (fig. 16). The intermediate form (fig. 14) is the most common. Variations in the shape of the funnels were apparently not related to differences in age of the embryos. The polar funnels were apparently not observed in this species by La Rue but similar funnels were described by Essex (1927) for Corallobothrium fimbriatum Essex.

The middle embryophore, 29 to 50 (average 38 ) microns in diameter, is suspended between the polar funnels usually in the middle but occasionally near one end of their axis (fig. 16). It comprises a distinct outside thin delimiting membrane, enclosing a zone, of variable thickness (averaging about 10 microns), of granular gelatinous material having an uneven inner surface. When the middle embryophore is broken the outer layer retains its continuity but the inner substance becomes scattered. This condition was also found by Magath (1929) in his study of the embryo of Crepidobothrium testudo (Magath). In "Ichthyotaenia filicollis Rud." Meggitt (1914) found that the middle embryophore is cellular in origin, derived from the zygote, provided with a pore through which the mature oncosphere regularly escapes, and that the granular substance is a residuum of the original yolk material. Thomas (1931) shows the middle embryophore of the mature embryo of Ophiotaenia saphena Osler to be distinctly cellular.

The inner embryophore is so thin and so closely adherent to the embryo, in intact specimens, as to be scarcely visible or measurable separately. The oncosphere with the inner membrane is 18 to 25 (average 21) microns in diameter. With gentle pressure on the cover glass the middle embryophore ruptures (the other two remaining intact) discharging the embryo through a small opening into the outer space (fig. 17). While escaping the embryo becomes temporarily elongate; it may pop out suddenly or gradually ooze out. When free the larva becomes spheroidal again and the inner embryophore expands and separates from the surface of the embryo.

The hooklets (figs. 15, 17) are of uniform size and shape and, in typical arrangement, one pair is median, and two pairs lateral. The hooklet, about 9.75 microns long, comprises a slender inner shaft, 6 by 0.75 microns, and a crescentic outer claw, 3.75 microns long, the axis of which is slightly oblique to the shaft.

\section{8}


The oncosphere, quiescent before its above-mentioned discharge from the middle embryophore, becomes active in from 40 to 60 seconds after its release. The activity increases to a maximum in from 2.5 to 4 minutes, then gradually subsides, ceasing entirely in from 10 to 15 minutes. The action involves a rhythmical spreading and retraction of the hooklets, the lateral pairs moving in unison and in alternation with the median pair. A few freshly collected embryonated eggs in tap water at atmospheric temperature (July) remained viable for 76 hours, although a majority died earlier.

\section{Experiments With CyCLOPES}

For experiments I used cestode-free specimens of $C y$ clops viridis (Jurine) and Microcyclops varicans (Sars) from a culture that had been kept under observation for over 5 months. For exposures the copepods were concentrated in finger bowls of water as free from organic matter as possible and supplied with large numbers of embryonated tapeworm eggs. Both species became readily infected although individuals of the larger species, $C$. viridis, acquired larger numbers of parasites, 14 being the maximum found in a single host.

After 24 hours liberated oncospheres were seen in both gut and body cavity of the host, the majority in the cephalothorax but a few as far back as the distal segment of the abdomen. Still spheroidal, now 20 to 32 microns in diameter (within the living cyclops), they exhibited constant but feeble movement of the hooklets. As the infections increased in age variation in degree of development of the parasites became more and more pronounced, especially in heavily infected hosts, the larger specimens apparently growing to the deprivation of the others. Indeed, in one large infection of 8 days duration the smallest specimen was no larger or more advanced than freshly hatched oncospheres. Similar variation was reported by Essex (1927) in his two species of Corallobothrium. To account for variation in rate of development the following possible factors suggest themselves: (1) degree of development of embryo when ingested, (2) size of host-parasites seem to thrive better in lighter infections.

At 48 hours the larger specimens, more elongate, now about 50 by 30 microns, show increased activity in the form of squirming movements that do not shift the general position of the parasite in the host. The hooklets are relatively less prominent against a more refractile background. By the fourth day a typical larva, measuring from 50 to 75 by 50 to 27 microns (one unusual specimen in extreme extension was 280 microns long) exhibits extraordinary plasticity. Like an amoeba it continually forms (and withdraws) blunt pseudopodium-like projections on any region of the body. At 5 days a large specimen varied from 91 to 105 microns in length.

At 7 days the larva (fig. 4) attains a length of 378 microns in extended condition. The "end organ" (now observed for the first time) is a distinctly 
outlined finely granular ovoidal body not visibly subdivided into cells. It is in immediate contact with the integument at the front end of the body. The acetabula are also recognizable as finely granular ovoidal bodies but they are smaller and less distinct, suggesting that they develop somewhat later than the "end organ." They are not flattened or cup-shaped and not in immediate contact with the integument. The integument of the developing scolex is generally external although subject to frequent temporary invagination. The cercomer is set off by a shallow constriction. Flame cells, an irregular distribution of numerous highly refractile calcareous corpuscles, and a vague suggestion of spination were first observed at this time.

\section{The Fully-Developed Procercoid}

I use the term procercoid although the larva is structurally much more advanced than the procercoid of Diphyllobothrium latum (Linnaeus). Joyeux and Baer (1929) refer to the corresponding stage in $I$. racemosa as a plerocercoid but it would seem that that term should be reserved for the larva in the second intermediate host. Embryo attains maximum development in cyclops in from 8 to 14 days. General form (figs. 2, 6, 7, 8, 10, 12) and measurements of an individual vary tremendously, depending on states of contraction and manner and extent of invagination, if any, of integument of scolex.

Embryo comprises body proper and tiny cercomer sharply separated by constriction. Body proper broadly pyriform with invaginated scolex (figs. $6,7,12$ ) or narrowly pyriform with everted scolex (fig. 8), large end forward in either case; general form changeable in response to movements and temporary constrictions. Number of original hooklets relegated to cercomer variable (figs. $4,8,11$ ) from 0 to 5 (no example with 6 was seen). Cercomer, often partly retracted (figs. 6,8) into an invagination at posterior end of body, apparently normally deciduous, the connection to the body becoming more and more attenuate (fig. 8 ) before disconnection. Detached cercomer, on microscope slide (fig. 5), and apparently also in cyclops, remains intact and motile for some time. Spination very fine, more pronounced anteriorly, general and of uniform distribution, even in suckers, and apparently, over cercomer. Cuticle much thicker than in younger stages. Parenchyma apparently differentiated into cortical and medullary regions in posterior part of body, since superficial portions were seen to slide readily over the less mobile and more hyaline central section.

The everted scolex has 4 longitudinal ridges (figs. 1, 2, 3) rounded posteriorly and narrowed anteriorly, each containing a sucker. Scolex generally withdrawn from external surface. Scolex may be withdrawn three different ways which I designate as inverted, retracted, and doubly invaginated. When inverted (fig. 7), integument of scolex proper is invaginated to form a tube, +-shaped in cross section (rays corresponding to grooves between longi- 
tudinal ridges) with small external mouth-like pore often guarded by four lip-like folds, end organ at bottom of tube posterior to suckers, and concavities of suckers directed mesially. When retracted (fig. 12), integument of neck region is invaginated to form vesicle into which scolex proper is withdrawn without change in shape. In double invagination (fig. 6) a combination of the other two states occurs. In everted and retracted scolices a little of the apical integument is generally retracted to form a shallow vestibule to the end organ. In extreme extension, vestibule disappears and end organ forms a slight apical protrusion (fig. 4). Scolex changes readily

\section{Explanation of Plate}

All figures concern Ophiotaenia perspicua La Rue. Figs. 1 to 12 , representing procercoids in various stages of development, were drawn free-hand from live specimens dissected from cyclopes. Ages indicate periods of residence in cyclops. Measurements in figs. 2, 4, and 11 represent extremes due to contraction and extension. Figs. 13 to 18 are camera lucida drawings of live embryonated eggs.

Figs. 1, 2, 3. Three views of an 8-day procercoid, 212-261 microns long, unusual because of the constriction in the body proper. Note multicellular end organ with its vestibule, calcareous corpuscles, urinary bladder, and cercomer.

Fig. 4. A 7-day procercoid, 60-102 microns long. Shows incipient end organ, acetabula and cercomer. Note occurrence of all hooklets on body - none on cercomer.

Fig. 5. A detached cercomer, $23 \times 40$ microns.

Fig. 6. Diagram of a mature procercoid with "doubly-invaginated scolex" and 5-hooked, partially retracted, cercomer.

FIG. 7. A 10-day procercoid, $159 \times 216$ microns, with "inverted" scolex. Note longitudinally flattened end organ.

Fig. 8. Mature procercoid, 630 microns in extended length, scolex freshly everted, suggests alternate manner in which couplets of opposed suckers are used. Shows 4-hooked cercomer nearly ready to detach, and acetabula larger than end organ.

FIG. 9. Two states of contraction of same slow-developing 7-day procercoid, 86 microns long, without calcareous corpuscles or evidence of differentiation.

FIG. 10. Anterior view of a longitudinally much contracted procercoid.

Fig. 11. A 7-day procercoid, 212-252 microns long, somewhat more advanced than specimen of the same age in Fig. 4.

FIG. 12. Diagram of much shortened procercoid showing "retracted scolex" and unicellular glands associated with end organ.

FIG. 13. Fully embryonated egg with unusually wide and short "polar funnels" in outer embryophore. Note middle embryophore closely investing an underlying layer of compacted granular substance and inner embryophore closely investing larva.

FIG. 14. Shows form of fully developed embryo most commonly encountered. Polar funnels are of typical form with embryo near center of their common axis.

FIG. 15. Oncosphere drawn especially to show form of hooklets two of which are seen at right angles to their axes. Portion of outer embryophore shown at right.

FIG. 16. Shows oncosphere lying near one end of common axis of unusually narrow polar funnels of outer embryophore.

Frg. 17. An oncosphere discharged from middle embryophore (ruptured by cover glass pressure) but still within inner and outer membranes. Note separation of inner membrane from embryo, this invariably occurs soon after escape from middle covering.

FIG. 18. Oncosphere seen with optical plane perpendicular to axis of polar funnels. 

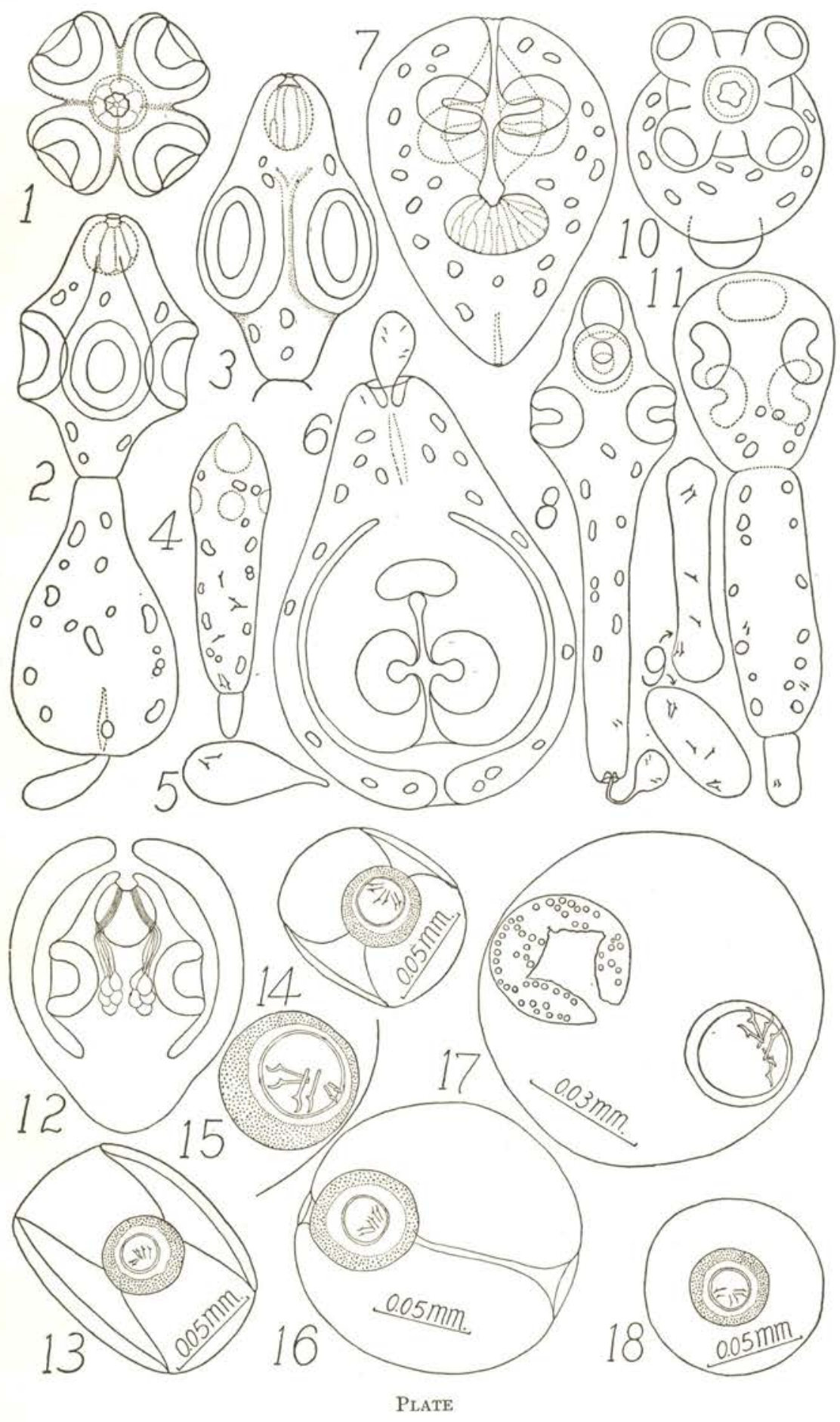
from one invaginated state to another with or without intervening eversion. Older specimens show tendency to keep scolex continuously invaginated. When the scolex is forcibly everted by cover glass pressure the larva often displays surprising and fascinating activity, for several minutes, progressing spatially by operating two opposed suckers in alternation with the other two (fig. 8), against the slide and cover glass.

End organ: ovoidal and longitudinally elongate in everted scolex, longitudinally flattened in inverted scolex; distinctly multicellular with longitudinally elongate, apparently glandular, cells (figs. 3, 7); only part of body showing pronounced affinity for neutral red; seemingly not at all muscular or capable of independent movement. Associated with the end organ there are some 20 to 30 (number not definitely determined) unicellular glands, of finely granular content, arranged apparently in 4 groups centrally situated at the level of, and adjacent to, the acetabula (fig. 12), with ducts running forward in 4 bundles, passing through the end organ between its cells, and leading to the vestibule. It would seem that the end organ with its complement of external gland cells may constitute a penetration apparatus to enable the procercoid to reach its proper locus in the next host. Acetabula apparently permanently cup-shaped and highly muscular.

Urinary bladder, a narrow irregular canal (fig. 7) in posterior part of body, gives rise to two pairs of longitudinal canals, the canals of one pair being apparently larger than those of the other. Flame cells and smaller tubules observed but arrangement not determined. Calcareous corpuscles numerous, variable in shape and size, superficial and irregular in distribution. Wagner (1917) found that in "Ichthyotaenia torulosa Batsch" the urinary bladder originates as an invagination of the external surface and is lined with cuticle. This did not appear to be at all true of the present form.

Measurements in microns taken from live pressure-free specimens removed from cyclops: body proper of 14 specimens with invaginated scolices, 146 to 364 (average 225) long by 60 to 182 (average 121) wide; 10 cercomers, 33 to 71 (average 49) long by 15 to 59 (average 36) wide; 6 end organs, transverse diameter 27 to 56 (average 37 ); acetabula, outside diameter 35 to 50 , inside diameter 27 to 30 ; one urinary bladder 25 long (in a parasite 146 long).

The effects of the parasites upon the host vary with the number of parasites in relation to the size of the host. A small cyclops, 875 microns long, was visibly affected by a single large procercoid (406 microns long, measured within the host). A larger cyclops may harbor several parasites with less noticeable inconvenience. Heavily infected hosts become definitely less active, less responsive to stimuli, and therefore more easily caught with a pipette. Thus in one experimental culture containing many cyclopes the 
incidence during the sixth to twelfth days of the infection appeared to be very high whereas after the twelfth day an infected cyclops was scarcely to be found, although disintegrating remains, supposedly of those that had been heavily infected, were abundant. The few parasitized individuals now captured were all large and harbored few procercoids.

The results of some feeding experiments suggest that when infected cyclopes are ingested by the fish Apomotis cyanellus the procercoids penetrate through the wall of the digestive tract and encyst in connective tissue. The experiments, however, were hardly subject to proper control and the results are inconclusive. This phase of the work is being repeated and continued by Mr. Eugene W. Hubbard for later publication.

\section{Discussion}

Following the classification adopted by La Rue (1914) proteocephalids in which the development of the procercoid has been described include (1) Ophiotaenia saphena Osler from Rana clamitans Latreille by Thomas (1931), (2) Ophiotaenia testudo Magath from Amyda spinifera (Le Sueur) by Magath (1929), (3) Ophiotaenia racemosa (Rudolphi) from Tropidonotus natrix Linné by Joyeux and Baer (1929), (4) Ophiotaenia perspicua La Rue (in this paper), (5) Corallobothrium gigantium Essex and (6) Corallobothrium fimbriatum Essex by Essex (1927), (7) Proteocephalus filicollis (Rudolphi) by Meggitt (1914), (8) Proteocephalus torulosus (Batsch) by Wagner (1917), (9) Proteocephalus percae (Müller) and (10) Proteocephalus longicollis (Zeder) by Kuczkowski (1925), (11) Protecocephalus ambloplitis (Leidy) by Hunter (1928) and Hunter and Hunter (1929), and (12) Proteocephalus penguis La Rue by Hunter (1929). The species listed above for Corallobothrium and Proteocephalus are all parasites of fishes.

C. testudo differs from $O$. perspicua in that: (1) the egg has only two embryophores, corresponding to the outer and middle membranes of my species, and polar funnels were not described for the outer embryophore; (2) the hooklets of the oncosphere are straighter, not fully formed until after the embryo hatches in cyclops, eventually all discarded with the cercomer, and reported to have their claws directed toward the center of the embryo before hatching, becoming reversed after hatching (the claws are always peripheral in $O$. perspicua); (3) the calcareous corpuscles of the young proceroid appear to be more regularly arranged in two lateral rows; and (4) the end organ, fully formed before the acetabula first appear, is considerably larger than the latter in the mature procercoid. O. racemos $a$ apparently differs from my species in lacking the inmost embryophore and the outer embryophoral funnels, in having a procercoid larger at corresponding ages and in including all the hooklets on the cercomer. The description of this form is brief and not illustrated. O. saphena agrees with my species in having three embryophores with polar funnels in the outer one and similarly 
shaped hooklets, but differs decidedly in that (1) the very young procercoid has a "clear bubble-like bladder... attached ... by a delicate membrane," (2) none of the hooklets go to the cercomer, (3) the cercomer has "large transparent cells," and (4) the end organ is a muscular "apical fifth sucker" similar in shape and size to the other suckers.

In the two species of Corallobothrium the oncosphere has only the two outer embryophores, the procercoid is regularly divided by constrictions into scolex, "middle portion," and cercomer, the latter being very transparent and described as "bladder-like." In C. fimbriatum the outer embryophore has polar funnels and the six hooklets are variously distributed to the middle portion and cercomer. In $C$. giganteum the polar funnels are lacking and the fate of the hooklets is not discussed. A constriction of the body proper into two regions was occasionally seen in young procercoids (figs. 2, 11) of my species, but the condition was exceptional and apparently temporary; it was never seen in older specimens.

In the Proteocephalus species only $P$. percae and $P$. longicollis have a cercomer and in $P$. percae, at least, the hooklets are retained by the body proper. The end organ is apparently absent in $P$. filicollis, small and vaguely defined in $P$. torulosus and $P$. percae, somewhat more distinct but not prominent in $P$. ambloplitis and $P$. penguis. Only $P$. ambloplitis appears to develop a persistently invaginated condition of the scolex. In all of the Proteocephalus forms the scolex region is very short in comparison with $O$. perspicua.

In the descriptions of none of the above-listed procercoids with which the present form is compared is there any mention of unicellular glands with ducts leading through the end organ, although the glands may correspond to a special multicellular region in the posterior part of the body in the procercoids of $P$. penguis and certain non-proteocephalid species. Furthermore cuticular spination is described for none except that in $P$. torulosus "Die auszere ... Schict ist in einem Besatz feiner Härchen und Borsten aufgelöst" (Wagner, 1917).

\section{SumMary}

1. Ophiotaenia perspicua La Rue is common in Natrix rhombifera (Hallowell) at Stillwater, Oklahoma.

2. Cuticular spination on the adult is reported apparently for the first time.

3. Observations on the structure of living fully embryonated eggs are recorded.

4. Cyclops viridis (Jurine) and Microcyclops varicans (Sars) were found experimentally to serve as first intermediate hosts of the tapeworm.

5. The procercoid becomes mature in from 8 to 14 days in July weather and attains a plerocercoid-like degree of development. 


\section{ORLANOMIA \\ AGRICOLTURAL \& MECHSNCAL COLLEG \\ L I B R A Y}

EARLY DEVELOPMENT OF OPHIOTAENIA PERSPICUAOCT 1291938

6. Outstanding structural features of the procercoid include cuticular spination, glandular non-muscular appearance of the prominent end organ (highly responsive to neutral red), and unicellular glands associated with the end organ.

7. The procercoid probably (experiments inconclusive) becomes an encysted plerocercoid in connective tissues of Apomotis cyanellus (Rafinesque).

\section{Literature Cited}

Anderson, M. G. 1935. Some intestinal parasites of Nalrix sipedon Linn., with notes on the identity of Ophiotaenia (Taenia) lactea Leidy with Ophiotaenia perspicua La Rue. Ohio Jour. Sci. 35: 79-80.

Essex, H. E. 1927. The structure and development of Corallobothrium with descriptions of two new fish tapeworms. Ill. Biol. Monogr. 11 (3): 1-74.

Hunter, G. W. III. 1928. Contributions to the life history of Proteocephalus ambloplitis (Leidy). Jour. Parasitol. 14: 229-242.

1929. Life-history studies on Proteocephalus pinguis La Rue. Parasitology. 21: 487-496.

Hunter, G. W. III. and Hunter, W. S. 1929. Further experimental studies on the bass tapeworm Proteocephahus ambloplitis (Leidy). Rept. Biol. Survey-Erie-Niagara System; Suppl. to 18th Ann. Rept. N. Y. State Conservat. Dept. 1929: 198-207.

Joyeux, C. and Baer, J. G. 1929. Sur le cycle evolutif d'un ténia de serpent. Compt. Rend. Séan. Acad. Sci. 188: 1838.

Kuczkowski, S. 1925. Die Entwicklung im Genus Ichthyotaenia Lönnb. Ein Beitrag zur Cercomertheorie auf Grund experimenteller Untersuchungen. Bull. Acad. Polon. Sci. Let., Cl. Sci. Math.-Nat. B. (1925): 423-446.

La Rue, G. R. 1911. A revision of the cestode family Proteocephalidae. Zool. Anz. 38: 473-482. 1914. A revision of the cestode family Proteocephalidae. Ill. Biol. Monogr. 1 $(1,2)$ : 350 .

Magath, T. B. 1929. The early life history of Crepidobothrium testudo (Magath 1924). Ann. Trop. Med. Parasitol. 23: 121-128.

Meggitt, F. J. 1914. The structure and life-history of a tapeworm (Ichthyotaenia filicollis Rud.) parasitic in the stickleback. Proc. Zool. Soc. London. 1: 113-138.

Thomas, L. J. 1931. Notes on the life history of Ophiotaenia saphena from Rana clamitans Latr. Jour. Parasitol. 17: 187-195.

1934. Further studies on the life cycle of a frog tapeworm Ophiotaenia saphena Osler. Jour. Parsitol. 20: 291-294.

Wagner, O. 1917. Ueber Entwicklungsgang und Bau einer Fischtaenie (Ichthyotaenia torulosa Batsch). Nebst Beiträgen zur Kenntnis einer Amphibientänie (Nematotaenia dispar Gze.). Jen. Zeitschr. Naturw. 55: 1-66.

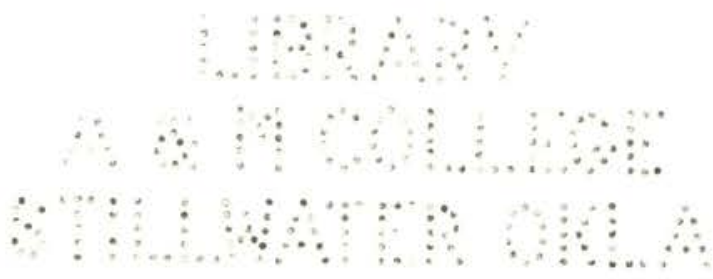




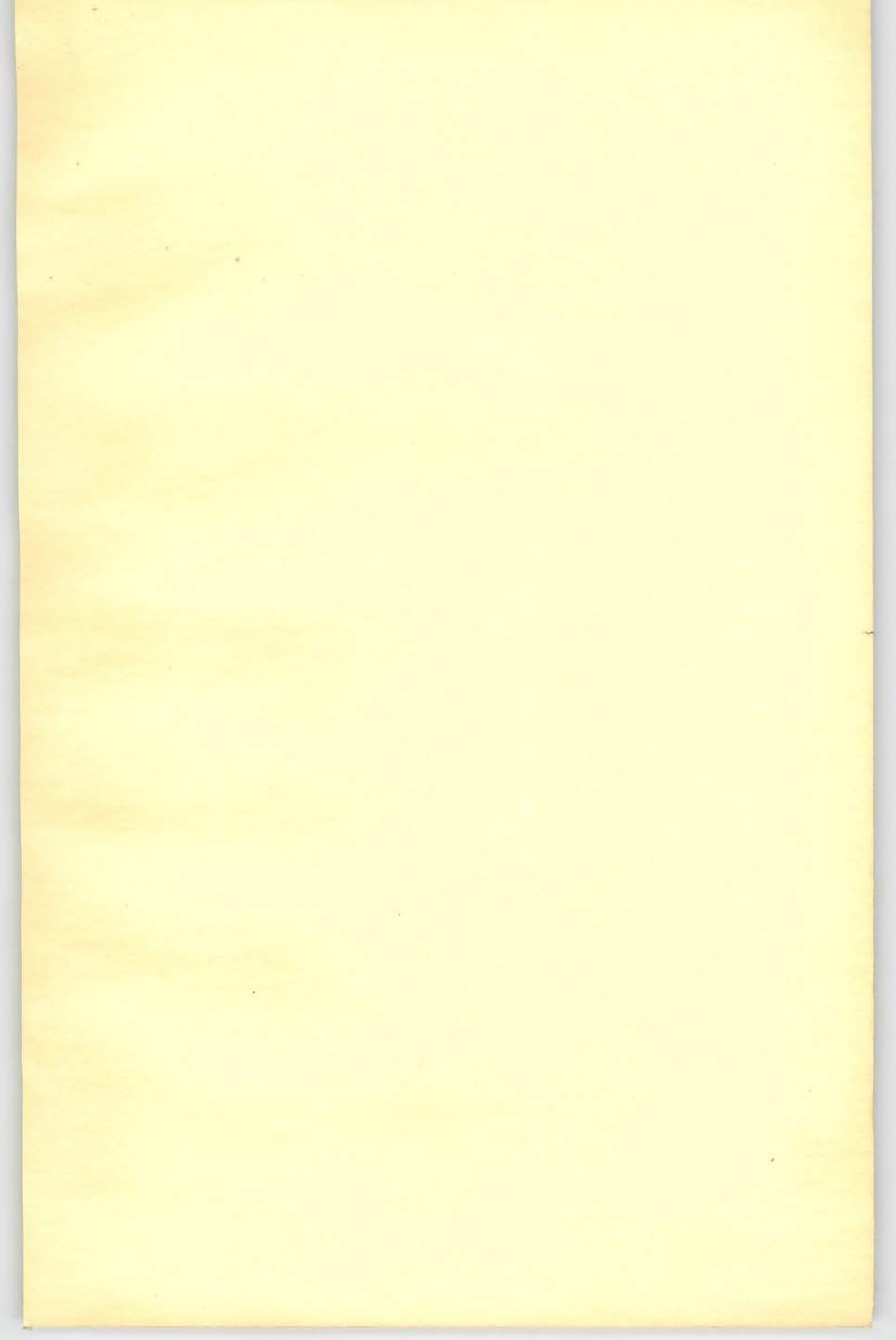

